\title{
Arctiin suppresses H9N2 avian influenza virus-mediated inflammation via activation of $\mathrm{Nrf} 2 / \mathrm{HO}-1$ signaling
}

Beixian Zhou ${ }^{1 \dagger}$, Linxin Wang ${ }^{2 \dagger}$, Yueyun Liang ${ }^{3}$, Jing $\mathrm{Li}^{4,5^{*}}$ and Xiping Pan ${ }^{2 *}$

\begin{abstract}
Background: H9N2 avian influenza viruses (AIVs) infect avian and mammalian hosts and provide internal genes for new emerging highly pathogenic avian viruses that cause severe pneumonia with high mortality, for which few medications are available. Arctiin, a bioactive lignan glycoside, has been reported to possess multiple pharmacological properties. However, the effect of arctiin on H9N2 virus infection is unclear. In the current study, we analyzed the effect of arctiin on H9N2 virus infection and the underlying molecular mechanism in vitro.
\end{abstract}

Methods: The antiviral effect against H9N2 virus was determined by plaque reduction assay (PRA) and progeny virus reduction assay. We employed MTT assay, qRT-PCR, ELISA, immunofluorescence and Western blotting to better understand the anti-inflammatory effect and corresponding mechanism of arctiin on H9N2 virus-infected cells.

Results: The results showed that arctiin had antiviral activity against H9N2 virus. Arctiin treatment reduced H9N2 virus-triggered proinflammatory cytokines, such as IL-6, and TNF-a. Moreover, arctiin significantly suppressed H9N2 virus-mediated expression of COX-2 and PGE . Furthermore, we found that arctiin inhibited H9N2 virus-mediated activation of RIG-I/JNK MAPK signaling. Interestingly, arctiin treatment obviously reversed H9N2 virus-induced reduction of Nrf2, increased the nuclear translocation of Nrf2, and upregulated Nrf2 signaling target genes (HO-1 and SOD2). Zinc protoporphyrin (Znpp) - an HO-1 inhibitor-weakened the inhibitory effect of arctiin on H9N2 virus-induced RIG-I/JNK MAPK and proinflammatory mediators.

Conclusion: Taken together, these results suggested that the anti-inflammatory effects of arctiin on H9N2 virus infection may be due to the activation of Nrf2/HO-1 and blocked RIG-I/JNK MAPK signaling; thus, arctiin may be a promising agent for prevention and treatment of H9N2 virus infections.

Keywords: Arctium lappa L., lignan, arctiin, H9N2 avian influenza virus, anti-inflammatory

*Correspondence: lijinghenan@163.com; xppan116@sina.com ${ }^{\dagger}$ Beixian Zhou and Linxin Wang contributed equally to this work. ${ }^{2}$ Guangzhou Laboratory, No. 9, XingDaoHuanBei Road, Guangzhou International Bio Island, Guangzhou 510005, China

${ }^{4}$ State Key Laboratory of Respiratory Disease, National Clinical Research Center of Respiratory Disease, Guangzhou Institute of Respiratory Health, the First Affiliated Hospital of Guangzhou Medical University, Guangzhou Medical University, NO. 195, Dongfengxi Road, Guangzhou 510120, China Full list of author information is available at the end of the article

\section{Introduction}

H9N2 avian influenza virus (AIV) was initially isolated in 1966 from turkeys in the United States [1]. It contains eight segments of single-stranded negative-sense RNA wrapped by a lipid bilayer envelope [1]. The natural hosts of H9N2 AIVs are wild birds and domestic poultry [2]. Although the infection with $\mathrm{H} 9 \mathrm{~N} 2$ virus in poultry usually causes subclinical to mild signs, it can also result in fatal outcomes in case of co-infection with bacteria or other microorganisms [3]. In recent years, the incidence

(c) The Author(s) 2021. Open Access This article is licensed under a Creative Commons Attribution 4.0 International License, which permits use, sharing, adaptation, distribution and reproduction in any medium or format, as long as you give appropriate credit to the original author(s) and the source, provide a link to the Creative Commons licence, and indicate if changes were made. The images or other third party material in this article are included in the article's Creative Commons licence, unless indicated otherwise in a credit line to the material. If material is not included in the article's Creative Commons licence and your intended use is not permitted by statutory regulation or exceeds the permitted use, you will need to obtain permission directly from the copyright holder. To view a copy of this licence, visit http://creativecommons.org/licenses/by/4.0/. The Creative Commons Public Domain Dedication waiver (http://creativeco mmons.org/publicdomain/zero/1.0/) applies to the data made available in this article, unless otherwise stated in a credit line to the data. 
of H9N2 virus cross-species transmission to humans has significantly increased. Serological surveys have revealed a high risk of H9N2 seropositivity in humans, indicating that $\mathrm{H} 9 \mathrm{~N} 2$ viruses have adapted to be able to infect humans [4]. It is remarkable that highly pathogenic avian influenza (e.g., H5N1 and H7N9) has acquired gene segments from $\mathrm{H} 9 \mathrm{~N} 2$ viruses, resulting in fatal respiratory diseases in humans $[5,6]$. The pandemic potential of H9N2 virus raises serious public health risks. Novel therapeutic strategies for treatment of $\mathrm{H} 9 \mathrm{~N} 2$ virus should be developed continually.

Host cells express various intracellular pattern recognition receptors (PRRs) that are capable of recognizing viral components and driving activation of diverse host signaling pathways to dictate the host's innate immune response against invading viruses [7]. Retinoic acid inducible gene-I (RIG-I), also known as DDX58, is a cytosolic PRR; it is well-characterized due to its crucial role in viral RNA sensing and initiating host defense [8]. Upon influenza virus (IV) infection, RIG-I engagement induces the activation of NF- $\mathrm{KB}$ and MAPKs (p38, ERK1/2, and JNK) signaling pathways, leading to the production of proinflammatory cytokines and chemokines, such as interferon beta (IFN- $\beta$ ), tumor necrosis factor alpha (TNF- $\alpha$ ), interleukin 6 (IL-6), interleukin 8 (IL-8), and interferon-gamma induced protein 10 (IP-10) [9]. However, numerous reports have revealed that uncontrolled proinflammatory states driven by these continuous signaling cascades often result in detrimental effects on the human respiratory system or even death [10]. Concomitantly, to successfully establish replication, AIVs utilize these signaling pathways to aid in progeny viral entry, viral ribonucleoprotein complex (vRNP) nuclear export, translation, and virion budding [11-13]. Therefore, targeting the host signaling may be a promising therapeutic strategy for respiratory diseases elicited by influenza virus, including $\mathrm{H} 9 \mathrm{~N} 2$ virus.

The transcription factor, NF-E2-related factor 2 (Nrf2), plays a critical role in antioxidant and anti-inflammatory processes [14]. Upon various stimuli, Nrf2 dissociates from Kelch-like ECH-associated protein 1 (Keap1) and translocates into the nucleus, which is followed by the transcription of an array of anti-inflammatory and antioxidant genes, such as Heme oxygenase-1 (HO-1), superoxide dismutase 2 (SOD2), and $\mathrm{NAD}(\mathrm{P}) \mathrm{H}$ quinone oxidoreductase 1 (NQO1) [14]. Genetic or pharmacological activation of the Nrf2 pathway could exert multiple beneficial effects, including anti-inflammatory, neuroprotective, and antiviral effects [15-18]. According to previous studies, the anti-inflammatory effects of Nrf2 signaling have been linked to the suppression of NF- $\mathrm{kB}$ signaling [19]. Recent studies have demonstrated that the activation of $\mathrm{Nrf} 2$ provided protective effects against
IV-mediated acute lung injury by suppressing viral replication and inflammation [15]. Increased expression of HO-1 has been found to limit IV replication via upregulation of interferon-induced antiviral effector proteins [20]. Therefore, we proposed that the activation of Nrf2 signaling by active compounds may help in the treatment of influenza-associated diseases.

Arctium lappa L. (burdock) is a medicinal plant with a number of pharmacological activities, including antihypertensive [21], antibacterial [22], antiviral [23], and anti-allergic effects [24]. Chemically, multiple bioactive compounds (e.g., lignan, flavonoid, polyphenol) have been extracted from Arctium lappa L. [25, 26]. Among these components, arctiin is a lignan glycoside that possesses various types of pharmacological properties [27]. For instance, arctiin has been shown to protect mice from lipopolysaccharide (LPS)-mediated acute lung injury via inactivation of PI3K/AKT signaling [28]. Arctiin was also found to increase virus-specific antibodies against influenza A (H1N1) virus [29]. However, the effects and the underlying mechanisms of arctiin against influenza virus infection have not yet been fully explored. In the current study, we aimed to investigate the effect of arctiin on H9N2 virus infection, but also the underlying molecular mechanism.

\section{Material and Methods}

\section{Preparation of extracts}

\section{Generals}

Silica gel 60 GF254 (Qingdao Haiyang) was used for vacuum liquid chromatography. Thin-layer Chromatography (TLC) was carried out using silica gel 60F254 and RP-18F254 plates (Merck). High-performance liquid chromatography (HPLC) was conducted using a Shimadzu system equipped with a LC-6 AD pump and a Diode Array Detector (SPD-M20A), as well as a Zorbax Eclipse XDB-C18 column $(9.4 \times 250 \mathrm{~mm}, 5 \mu \mathrm{m}$ particle size, Agilent); mobile phase acetonitrile - water $(9: 1 \mathrm{v} / \mathrm{v})$; flowrate $1 \mathrm{~mL} / \mathrm{min}$, injection volume $500 \mu \mathrm{L}$, wavelength $254 \mathrm{~nm}$ and $365 \mathrm{~nm}$. HPLC solvents were purchased from Merck.

\section{Extraction of arctiin}

The plant materials were purchased from Bozhou traditional Chinese Medicine Market (Anhui provicine, China) and identified as dried seeds of Arctium lappa $L$ by Professor Xiping Pan in Guangzhou laboratory. All solvents were purchased from Damao Chemical Reagent Factory (Tianjin, China). The dried seeds $(2 \mathrm{~kg})$ were extracted with $95 \%$ ethanol $(3 \times 4 \mathrm{~L}, 1 \mathrm{~h}$ each) in reflux. The ethanol solution was concentrated under reduced pressure to obtain a crude extract $(165 \mathrm{~g})$. The extract was chromatographed on a silica gel (200-300 mesh) column 
using dichloromethane - methanol mixed solvent as gradient eluent (from 10:1 to 1:1) to obtain fractions $\mathrm{A}-\mathrm{H}$. Fraction $\mathrm{E}$ was further purified by recrystallization to afford a white crystalline powder $(58.6 \mathrm{mg})$, which was identified as the known compound arctiin by ${ }^{1} \mathrm{H}$ and ${ }^{13} \mathrm{C}$ NMR spectral data analysis.

\section{Cell culture}

A549 cells and Madin-Darby canine kidney (MDCK) cells purchased from American Type Culture Collection (ATCC; Manassas, VA, USA) were stored in liquid nitrogen in our laboratory. After thawing in a $37^{\circ} \mathrm{C}$ water bath, the cells were cultured at $37^{\circ} \mathrm{C}$ in DMEM medium containing $10 \%$ fetal bovine serum.

\section{Virus and viral infection}

AIVs A/Hongkong/Y280/97 (H9N2) were purchased from ATCC and propagated in the allantoic cavities of 10-day-old embryonated chicken eggs. The viral titers were determined in confluent monolayers of MDCK cells as described previously [30]. Briefly, cells were infected with 10-fold serial dilutions of the virus stocks, and then covered with a mixture of serum-free MDEM, $1 \%$ agarose and $1 \mu \mathrm{g} / \mathrm{ml}$ of Trypsine TPCK. After incubation at $37^{\circ} \mathrm{C}$ for $48 \mathrm{~h}$, cells were stained with $0.1 \%$ crystal violet for viral plaque count. Aliquots of $\mathrm{H} 9 \mathrm{~N} 2$ viruses were stored at $-80^{\circ} \mathrm{C}$.

For viral infection, A549 cells were grown to confluent monolayers and then washed twice with PBS. Next, serum-free DMEM medium containing 0.1 multiplicities of infection (MOI) of $\mathrm{H} 9 \mathrm{~N} 2$ virus was added to the cells. After $2 \mathrm{~h}$ of incubation at $37^{\circ} \mathrm{C}$, the inoculum was replaced by fresh serum-free DMEM medium containing various concentrations of compounds for $24 \mathrm{~h}$.

\section{Antiviral assays}

To determine antiviral effect of arctiin against H9N2 virus, we used plaque reduction assay (PRA) and progeny virus reduction assay. For the PRA, monolayers of MDCK cells were inoculated with H9N2 virus (100 PFU/ well) for $2 \mathrm{~h}$, and then replaced with DMEM containing $0.8 \%$ agarose with or without indicated concentration of arctiin. After $48 \mathrm{~h}$, the cells were fixed by $10 \%$ paraformaldehyde and stained with $0.1 \%$ crystal violet for viral plaques' visualization. For progeny virus reduction assay, A549 cells were infected with $\mathrm{H} 9 \mathrm{~N} 2$ virus $(\mathrm{MOI}=0.1)$ in the presence or absence of arctiin for $24 \mathrm{~h}$. Then, progeny virus titers in the culture supernatants were measured on MDCK cells.

\section{Cell viability assay}

The viability of A549 cells with indicated concentration of arctiin treatment was evaluated using 3-(4,5-dimethylthiazol-2-yl)-2,5-diphenyltetrazolium bromide (MTT) assay. In brief, A549 cells $\left(1 \times 10^{5}\right.$ cells per well) were grown onto 96-well plates and cultured overnight at $37^{\circ} \mathrm{C}$ in $5 \% \mathrm{CO}_{2}$. The culture supernatants were discarded and replaced with mediums containing arctiin of various concentrations $(0-800 \mu \mathrm{g} / \mathrm{mL})$ for 24 , 48 and $72 \mathrm{~h}$. After that, $10 \mu \mathrm{L}$ of MTT solution $(5 \mathrm{mg} / \mathrm{mL})$ was added to each well and incubated at $37^{\circ} \mathrm{C}$ for additional $4 \mathrm{~h}$. Then, the culture medium was discarded and $100 \mu \mathrm{L}$ of DMSO was added to each well for formazan crystals dissolution. Optical density was measured with a microplate reader at a wavelength of $570 \mathrm{~nm}$ (Thermo Scientific Varioskan Flash, USA).

\section{Real-time quantitative PCR}

TRIzol reagent was used to extract total RNA from A549 cells. Then, it was processed with cDNA synthesis by using a PrimeScript RT-PCR Kit (Takara). Real-time PCR was conducted on Applied Biosystems 7500 using the following thermocycling: $94^{\circ} \mathrm{C}$ for $30 \mathrm{~s}$, followed by 40 cycles of $94^{\circ} \mathrm{C}$ for $5 \mathrm{~s}$ and $60^{\circ} \mathrm{C}$ for $34 \mathrm{~s}$. The mRNA levels of the target genes were normalized to the GAPDH mRNA level by using a $2^{-\triangle \triangle C T}$ method [31]. $\Delta \Delta \mathrm{Ct}=\left(\mathrm{Ct}_{\text {target }}\right.$ $\left.-\mathrm{Ct}_{\text {GAPDH }}\right)_{\text {treatment }}-\left(\mathrm{Ct}_{\text {target }}-\mathrm{Ct}_{\mathrm{GAPDH}}\right)_{\text {control }}$ Table 1 shows the primers and probes that we used.

\section{ELISA}

H9N2 virus-infected A549 cells were treated with various concentrations of arctiin. After $24 \mathrm{~h}$, culture supernatants were collected and centrifuged at $10,000 \mathrm{~g}$ for $15 \mathrm{~min}$ to remove the dead cells and cell debris. Next, the levels of proinflammatory cytokines in the culture supernatants were assayed using ELISA kits (IL-6 and TNF- $\alpha$ ) in accordance with the manufacturers' instructions (Multiscience, Hangzhou, China). The absorbance

Table 1 Primers and Probe Sequences for Real-time PCR

\begin{tabular}{lll}
\hline Gene & Primers and Probes & Sequence $\left(\mathbf{5}^{\prime} \rightarrow \mathbf{3}^{\prime}\right)$ \\
\hline IL-6 & Forward & CGGGAACGAAAGAGAAGCTCTA \\
& Reverse & CGCTTGTGGAGAAGGAGTTCA \\
& Probe & TCCCCTCCAGGAGCCCAGCT \\
TNF-a & Forward & AACATCCAACCTTCCCAAACG \\
& Reverse & GACCCTAAGCCCCCAATTCTC \\
& Probe & CCCCCTCCTTCAGACACCCTCAACC \\
COX-2 & Forward & GAATCATTCACCAGGCAAATTG \\
& Reverse & TTTCTGTACTGCGGGTGAAC \\
& Probe & TTCCTACCACCAGCAACCCTGCCA \\
GAPDH & Forward & GAAGGTGAAGGTCGGAGTC \\
& Reverse & GAAGATGGTGATGGGATTTC \\
& Probe & CAAGCTTCCCGTTCTCAGCC
\end{tabular}


was measured at a wavelength of $450 \mathrm{~nm}$ with correction at $570 \mathrm{~nm}$ by a microplate reader (Multiskan FC, Thermo Fisher Scientific, MA, USA).

\section{Western blot analysis}

Confluent monolayers of A549 cells in a six-well plate, infected with H9N2 viruses, were treated with various concentrations of arctiin. After $24 \mathrm{~h}$, the cells were washed twice with PBS and lysed in ice-cold RIPA buffer (Beyotime, shanghai, China) supplemented with protease inhibitor cocktail (Sigma-Aldrich) and $1 \mathrm{mM}$ phenylmethanesulfonyl fluoride (PMSF; Sigma-Aldrich). Cellular lysates were collected and centrifuged for $15 \mathrm{~min}$ at $10,000 \mathrm{~g}$ at $4{ }^{\circ} \mathrm{C}$ to remove debris. Then, protein concentration of the supernatant was measured by BCA Protein Assay Kit (Thermo Scientific, Waltham, MA, USA). Afterward, $20 \mu \mathrm{g}$ of total protein from each sample was fractionated by $10 \%$ SDS-PAGE. After transfer of the resolved protein onto 0.2- $\mu \mathrm{m}$ PVDF membranes, the membranes were blocked with $5 \%$ nonfat milk and incubated with primary antibodies overnight at $4{ }^{\circ} \mathrm{C}$. Then, the membranes were washed three times with

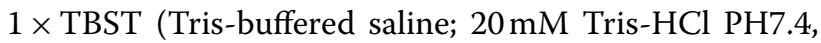
$150 \mathrm{mM} \mathrm{NaCl}, 0.1 \%$ Tween 20) and further incubated with HRP-conjugated secondary antibody (Multiscience, Hangzhou, China) (1:5000 dilution) for $1 \mathrm{~h}$ at room temperature. The bands were detected by a chemiluminescence kit (PerkinElmer).

\section{Immunofluorescence staining}

For Nrf2 nuclear translocation assay, A549 cells $\left(1 \times 10^{4}\right.$ cells/well) seeded onto glass slides $(9 \mathrm{~mm}$, diameter) were incubated in $5 \% \mathrm{CO}_{2}$ at $37^{\circ} \mathrm{C}$ overnight. Then, A549 cells were infected with $\mathrm{H} 9 \mathrm{~N} 2$ viruses and treated with or without arctiin. After $24 \mathrm{~h}$, the cells were washed three times with PBS, fixed with methanol for $20 \mathrm{~min}$, and permeabilized with $0.5 \%$ Triton X-100 for $15 \mathrm{~min}$. Then, they were blocked with $5 \%$ BSA for $30 \mathrm{~min}$ at room temperature and stained with rabbit polyclonal anti-Nrf2 antibody $(1: 200)$ overnight at $4{ }^{\circ} \mathrm{C}$. Next day, the cells were incubated with FITC-conjugated goat anti-rabbit secondary antibody (1:200; MultiSciences, Hangzhou, China) for $1 \mathrm{~h}$ at room temperature, and cellular nuclei were stained with DAPI. The glass slides were sealed with glycerin, and imaging was performed with ZEISS Axio Imager.D2 microscope (ZEISS, Hamburg, Germany).

\section{Data analysis}

One-way ANOVA followed by Tukey's multiple comparison test was used for comparison between groups. Probability levels less than $0.05(P<0.05)$ were considered significant. SPSS 18.0 software (SPSS, Inc., Chicago, IL,
USA) was used for data analysis, and variables were presented as mean \pm standard deviation (SD).

\section{Results}

Structure, cytotoxicity and antiviral effects of arctiin Arctiin isolated from Arctium lappa L. was confirmed by NMR spectroscopy. White powder, ESI-MS $\mathrm{m} / z$ $552.1\left[\mathrm{M}+\mathrm{NH}_{4}\right]^{+} ;{ }^{1} \mathrm{H}-\mathrm{NMR}\left(\mathrm{CDCl}_{3}, 500 \mathrm{MHz}\right), \delta: 6.92$ $(1 \mathrm{H}, \mathrm{d}, \mathrm{J}=8.0 \mathrm{~Hz}, \mathrm{H}-5), 6.82\left(1 \mathrm{H}, \mathrm{m}, \mathrm{H}-5^{\prime}\right), 6.75(1 \mathrm{H}, \mathrm{m}$, $\mathrm{H}-2), 6.64\left(1 \mathrm{H}, \mathrm{m}, \mathrm{H}-2^{\prime}\right), 6.56(1 \mathrm{H}, \mathrm{m}, \mathrm{H}-6), 6.49(1 \mathrm{H}$, m, H-6'), 4.80 (1H, s, Glu-1"1), 4.12 (1H, m, H-9'a), 3.83 (1H, m, H-9'b), 3.79-3.70 (9H, m, -OMe), 2.86 (2H, m, H-7), 2.63 (1H, m, H-7’a), 2.55(1H, m, H-8), 2.47 (1H, m, H7'b); ${ }^{13} \mathrm{C}-\mathrm{NMR}\left(\mathrm{CDCl}_{3}, 125 \mathrm{MHz}\right), \delta: 178.6$ (C-9), 150.0 (C-3), 149.2 (C-3'), 148.0 (C-4), 145.1 (C-4'), 133.6 (C-1), $130.4\left(\mathrm{C}-1^{\prime}\right), 121.9\left(\mathrm{C}-6^{\prime}\right), 121.0(\mathrm{C}-6), 118.0(\mathrm{C}-5), 113.4$ $\left(\mathrm{C}-2^{\prime}\right), 112.2(\mathrm{C}-2), 111.6\left(\mathrm{C}-5^{\prime}\right), 102.4\left(\mathrm{glu}-1^{\prime \prime}\right), 76.0-77.3$ (glu-2", 3" $\left.4^{\prime \prime}, 5^{\prime \prime}\right), 71.2\left(\mathrm{C}-9^{\prime}\right), 61.8\left(\mathrm{C}-6^{\prime \prime}\right), 56.0$ (3, 4, 5'-OMe), 46.5 (C-8), 41.2 (C-8'), 38.1 (C-7'), 34.5 (C-7). The data were in accordance with the document of arctiin (Fig. 1A) [32]. Then, the antiviral effect against H9N2 influenza avian virus was confirmed by PRA and progeny virus reduction assay (Fig. 1B-D). Before the analysis of the pharmacological action, an MTT assay was employed to assess whether treatment with arctiin would induce direct cytotoxicity to A549 cells. Treatment with arctiin at a concentration ranging from 0 to $800 \mu \mathrm{g} / \mathrm{mL}$ for 24,48 and $72 \mathrm{~h}$ did not affect the viability of A549 cells (Fig. 1E). And, we used doses of arctiin $\leq 300 \mu \mathrm{g} / \mathrm{mL}$ in the following experiments.

\section{Arctiin inhibits H9N2 avian influenza virus-mediated proinflammatory response}

Infection with $\mathrm{H} 9 \mathrm{~N} 2$ influenza avian viruses triggers intense inflammation, which results in disease severity [33]. Previous reports have indicated anti-inflammatory properties of arctiin in response to various stimuli [28, 34]. Therefore, we hypothesized that arctiin could reduce the expression levels of proinflammatory cytokines elicited by $\mathrm{H} 9 \mathrm{~N} 2$ viruses. As expected, the results showed that the increased mRNA levels of proinflammatory cytokines (including IL-6 and TNF- $\alpha$ ) upon H9N2 virus infection were significantly suppressed by arctiin treatment (Fig. 2A). Consistently, elevated secretion of these proinflammatory mediators in the culture supernatant was also effectively inhibited by arctiin (Fig. 2B). It has been reported that $\mathrm{COX}-2$ and its lipid metabolite $\mathrm{PGE}_{2}$ are critical inflammation mediators and associated with viral pneumonia progression [35]. Here, we found that treatment with arctiin decreased $\mathrm{H} 9 \mathrm{~N} 2$ virus-mediated expression of COX-2 at mRNA and protein levels in a dose-dependent manner (Fig. 2C-E). Meanwhile, production of $\mathrm{PGE}_{2}$ was detected by ELISA; as shown in 


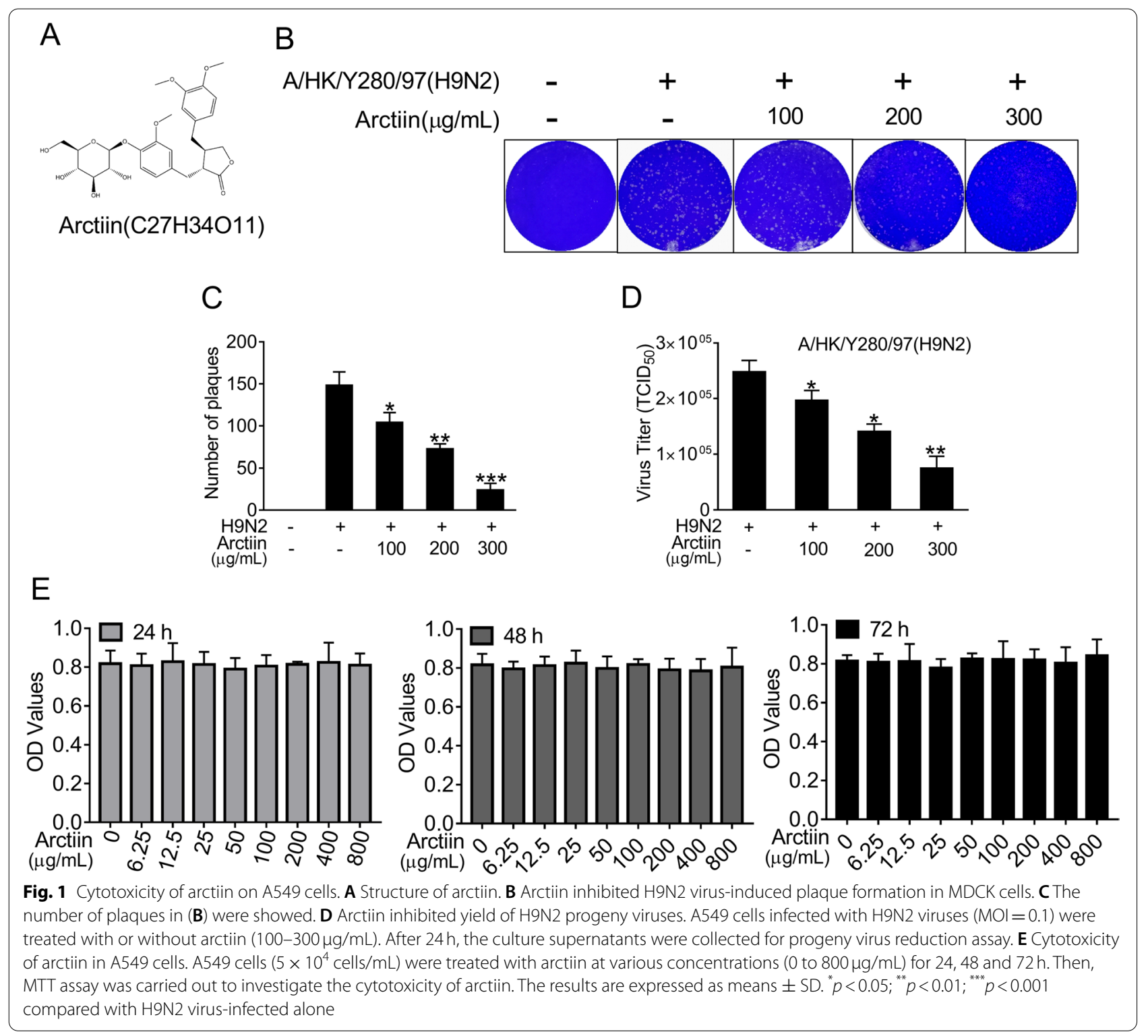

Fig. 2F, treatment with arctiin significantly reduced H9N2-induced increased levels of $\mathrm{PGE}_{2}$. These results indicate that arctiin can attenuate $\mathrm{H} 9 \mathrm{~N} 2$ virus-mediated inflammation.

\section{Arctiin attenuates H9N2 avian influenza virus-mediated activation of P-JNK MAPK signaling}

H9N2 virus infection activates host cellular signaling cascades and thus triggers severe pneumonia [33]. To understand the anti-inflammatory mechanism of arctiin, we next focused on the effect of arctiin on H9N2 virus-mediated cellular signaling pathways. RIG-I is a PRR for recognition of influenza A virus-derived 5'ppp-RNA, resulting in downstream MAPK signaling pathway activation [9].
We therefore investigated the effects of arctiin on the expression of RIG-I during H9N2 virus infection. A549 cells infected by $\mathrm{H} 9 \mathrm{~N} 2$ virus markedly induced RIG-I expression. However, arctiin treatment of H9N2 virusinfected cells potently suppressed RIG-I expression (Fig. 3A and B). Considering the inhibitory effect of arctiin on RIG-I, it is possible that the downstream signaling pathways of RIG-I would be inhibited by arctiin treatment. Accordingly, western blot demonstrated that activation of JNK MAPK mediated by H9N2 viruses, but not NF-kB, ERK1/2, and p38 MAPK, was inhibited by arctiin (Fig. $3 \mathrm{C}$ and $\mathrm{D}$ ). Therefore, these results indicate that arctiin dampens H9N2 virus-mediated inflammation by blocking the RIG-I/JNK signaling pathway. 


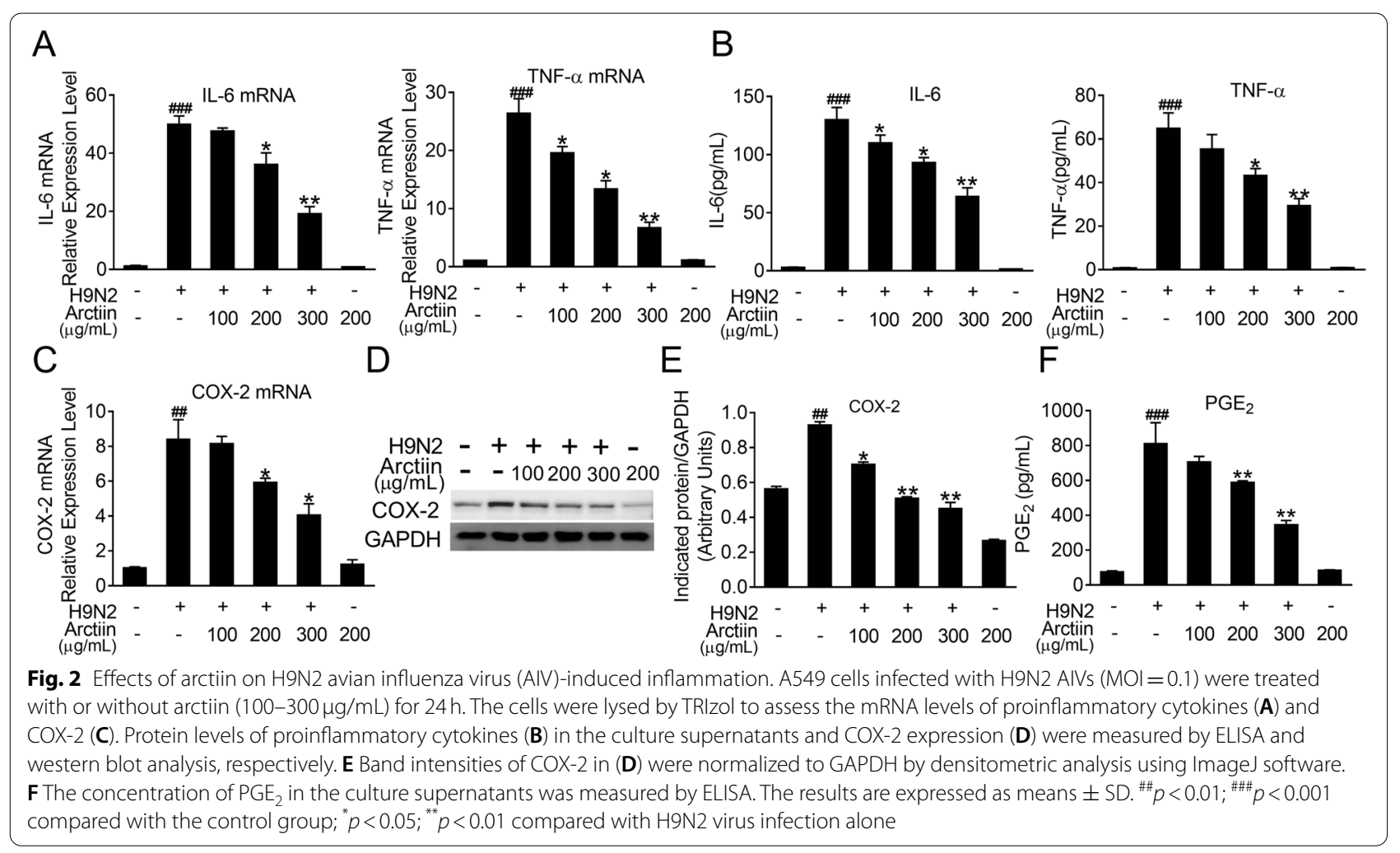

\section{Arctiin treatment activates Nrf2 signaling in H9N2 avian influenza virus-infected cells}

Upon viral infection, the Nrf2 signaling pathway resolves excessive proinflammatory response [15]. To further clarify the anti-inflammatory role of arctiin in H9N2 virus infection, the effects of arctiin on Nrf2 signaling were investigated using western blot analysis. The results showed that Nrf2 expression significantly decreased in H9N2 virus-infected A549 cells. However, arctiin treatment reversed the inhibitory effect of $\mathrm{H} 9 \mathrm{~N} 2$ on $\mathrm{Nrf} 2$ expression (Fig. 4A and B). Moreover, the H9N2 virusmediated the decreased in the main effectors of $\mathrm{Nrf} 2$ signaling (HO-1 and SOD2) was rescued by arctiin treatment (Fig. 4A and B). Moreover, immunofluorescence staining demonstrated that arctiin treatment increased the accumulation of nuclear Nrf2 in response to H9N2 virus infection (Fig. 4C). Therefore, we assume that the anti-inflammatory effects of arctiin may be associated with the activation of $\mathrm{Nrf} 2$ signaling.

\section{HO-1 inhibition reverses the inhibitory effects of arctiin on RIG-I/P-JNK MAPK signaling}

To further confirm whether the anti-inflammatory effect of arctiin is associated with the activation of Nrf2 signaling, we performed western blotting to detect the RIG-I/ JNK signaling in H9N2 virus-infected A549 cells with
Znpp (HO-1 inhibitor) or in combination with arctiin treatment. Notably, the reduction of H9N2 virus-mediated RIG-I expression by arctiin was abrogated in cells with Znpp pretreatment (Fig. 5A and B). Meanwhile, the inhibitory effect of arctiin on the activation of JNK MAPK was also reversed by HO-1 inhibition (Fig. 5A and B). Therefore, arctiin inhibits H9N2 virus-mediated RIGI/P-JNK MAPK signaling via activation of Nrf2 signaling.

HO-1 inhibition abrogates the anti-inflammatory effects of arctiin in H9N2 avian influenza virus-infected A549 cells Given that the inhibitory effect of arctiin on RIG-I/JNK MAPK signaling was abrogated by $\mathrm{HO}-1$ inhibition, we next investigated whether the anti-inflammatory effect of arctiin on H9N2 virus-mediated expression of proinflammatory mediators was reversed in cells with Znpp pretreatment. As shown in Fig. 6A and B, Znpp pretreatment in $\mathrm{H} 9 \mathrm{~N} 2$ virus-infected cells abrogated the inhibitory effect of arctiin on the mRNA levels and protein levels of proinflammatory cytokines, including IL-6 and TNF- $\alpha$. Similarly, the reduction of COX-2 and $\mathrm{PEG}_{2}$ expression by arctiin was reversed by $\mathrm{Znpp}$ pretreatment (Fig. 6C-F). Therefore, these results suggest that the antiinflammatory effects of arctiin involve $\mathrm{Nrf} 2 / \mathrm{HO}-1$ activation, which results in suppression of $\mathrm{H} 9 \mathrm{~N} 2$ virus-induced RIG-I/JNK MAPK signaling. 


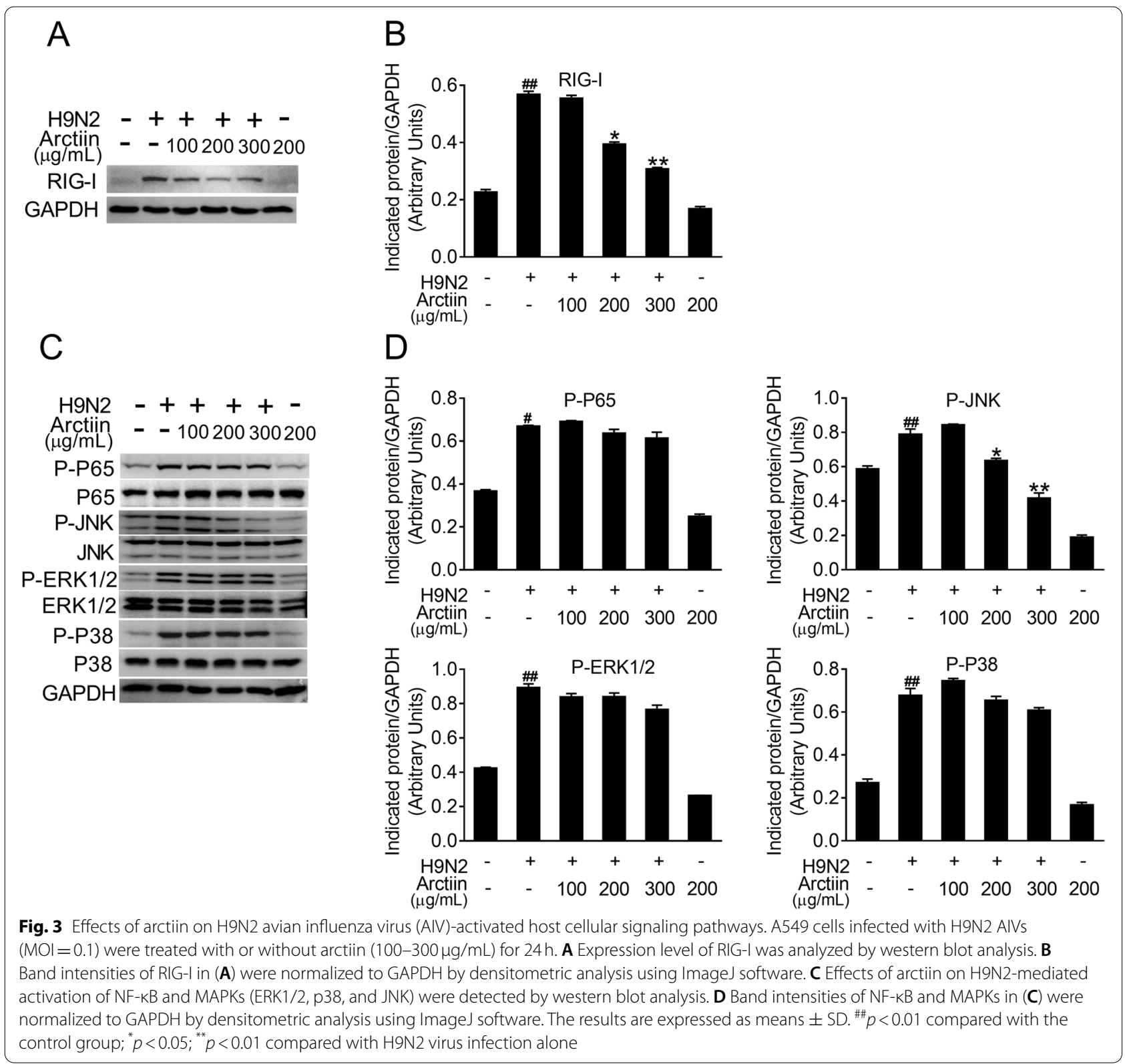

\section{Discussion}

Globally, the circulation of H9N2 AIVs among avian species provided gene segments to generate novel lethal viruses (e.g., $\mathrm{H} 5 \mathrm{~N} 1$ and $\mathrm{H} 7 \mathrm{~N} 9$ ), posing a serious threat to public health $[5,6]$. Rapid mutation and reassortment of viruses have led to vaccine inefficacy and resistance to antiviral agents (adamantane and oseltamivir) [36], so there are few effective therapy options for influenza diseases. Arctiin is the effective component of Arctium lappa $L$. that has been reported to possess anti-inflammatory, antiviral, antioxidant, and antitumor properties [28, 36-39]. However, the effect of arctiin on H9N2 AIV infection has not yet been reported, and the corresponding mechanism needs to be clarified. Here we reported that arctiin reduced H9N2 AIV replication. Our further experiments revealed that arctiin treatment reduced H9N2 virus-mediated inflammation via activation of the Nrf2/HO-1 pathway, resulting in the blockade of RIGI/P-JNK signaling. According to our study, the activation of the Nrf2/HO-1 pathway is likely to contribute to the antiviral and anti-inflammatory effects of arctiin; hence, arctiin may provide an alternative strategy to limit transmission of $\mathrm{H} 9 \mathrm{~N} 2$ viruses. 

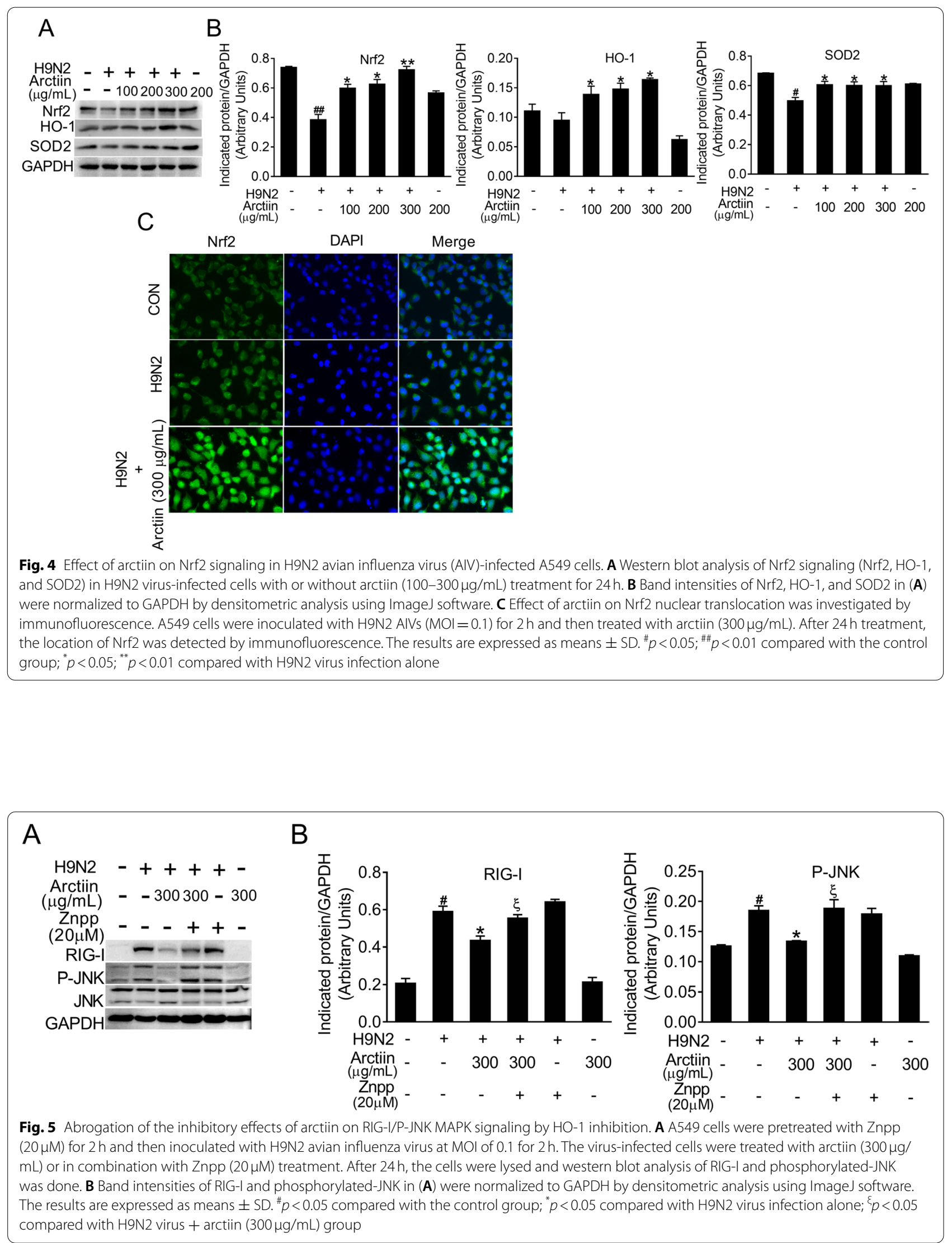


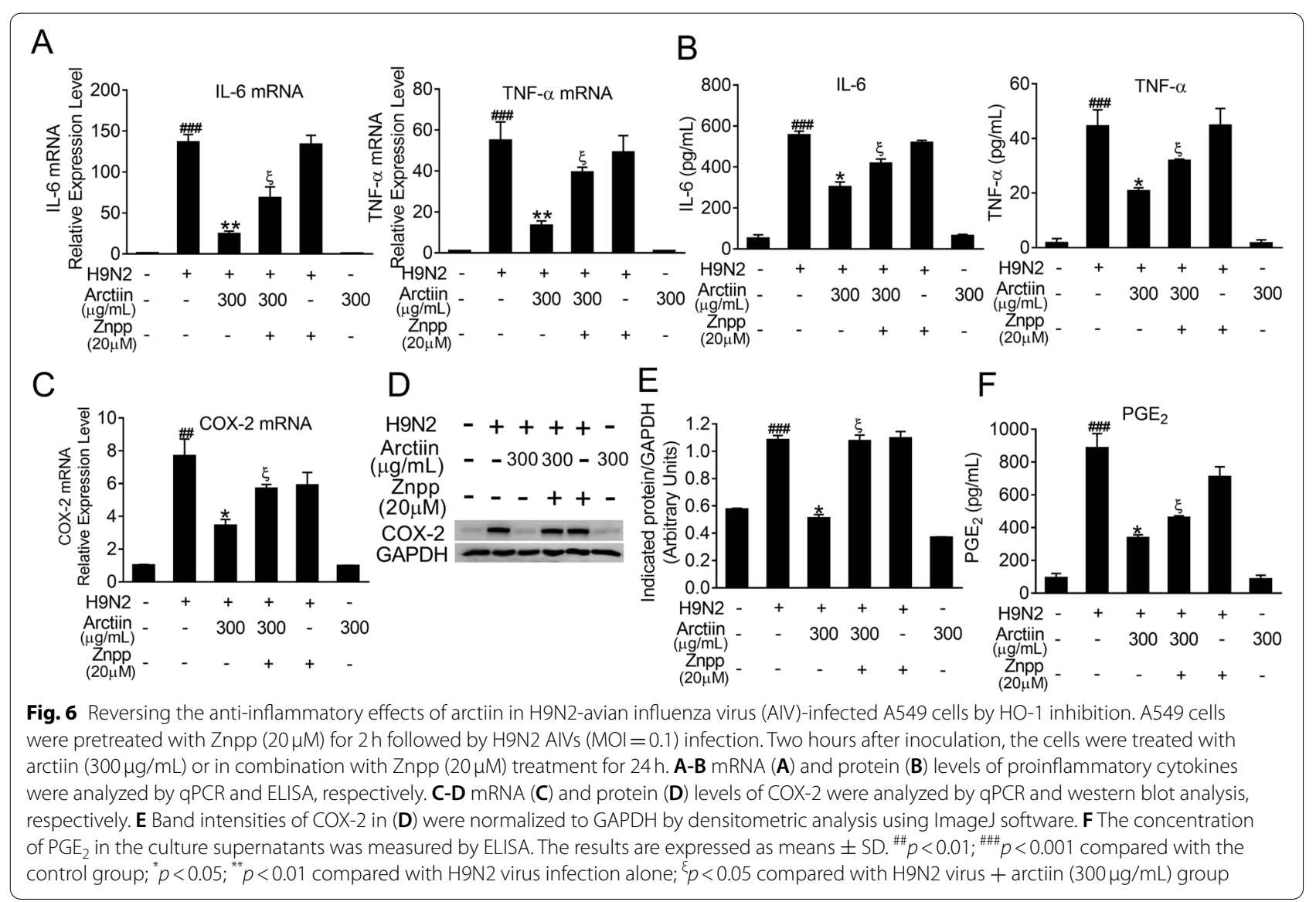

Our results showed that arctiin inhibited H9N2 virus replication, as evidenced by the results of PRA and progeny virus reduction assay. A previous study showed that arctiin treatment could increase virusspecific antibodies [29], but the mechanism involved in its effects on host signaling linked to antiviral effects was not reported. The replication of IAV, including H9N2 virus, is dependent on the activation of host cellular signaling [40]. During viral infection, the activation of NF-kB and ERK1/2 MAPK signaling has been reported to support viral ribonucleoprotein nuclear export $[11,40]$. Besides, JNK signaling is also involved in IV life cycle. Inhibition of JNK by its specific inhibitor SP600125 decreased synthesis of vial genomic RNA (vRNA) and structural proteins [41]. Viral nucleoprotein hijacked cellular Filamin A, resulting in activation of the JNK pathway to promote virus efficient replication. In vivo studies demonstrated that JNK inhibition reduced virus titer and alleviated virus-mediated lung injury [42]. Our present study showed that arctiin suppressed H9N2 virus-mediated JNK activation. Therefore, we supposed that the mechanism by which arctiin exerted antiviral effects on H9N2 virus might be related to its inhibition of the JNK pathway.

The transcription factor Nrf2 is a restriction factor to limit the replication of multiple viruses, including IAV. The anti-influenza mechanism of Nrf2 involves the inhibition of virus entry [43]. Moreover, the antioxidative enzyme HO-1, a downstream effector of Nrf2, has been reported to strengthen generation of type I IFNs and IFN-stimulated genes (ISGs) (IFIT1, OAS1, and IFITM3), leading to reduced IAV titers [20, 44]. Our findings demonstrated that the impaired expression of Nrf2 and Nrf2 target genes (HO-1 and SOD2) by H9N2 virus was reversed by arctiin treatment. As indicated above, the anti-H9N2 virus effects of arctiin may be associated with the activation of the Nrf2 signaling pathway.

In addition to its anti-H9N2 virus effects, arctiin suppressed H9N2 virus-induced inflammation. The antiinflammatory properties of arctiin have been reported previously. Arctiin treatment dose-dependently reduced LPS-mediated upregulation of IL- 6 , TNF- $\alpha$, and IL-1 $\beta$, as well as reduction of $\mathrm{PGE}_{2}$ and $\mathrm{NO}$ [45]. Besides, arctiin showed the potential therapeutic effects in depression by attenuation of neuroinflammation [34]. However, 
this is the first report to investigate the regulatory role of arctiin in $\mathrm{H} 9 \mathrm{~N} 2$ virus-mediated inflammation. Here, we found that arctiin treatment reversed H9N2 virus-elicited upregulation of proinflammatory mediators (IL-6, TNF- $\alpha$, COX-2, and $\mathrm{PGE}_{2}$ ). Accumulated evidence has demonstrated that the magnitude and duration of inflammation are linked to the outcome of influenza diseases [46]. An appropriate immune response is capable of controlling viral infection without simultaneously leading to lung damage [46]. Highly pathogenic AIVs (H5N1 and H7N9)-triggered viral pneumonia with robust cytokine production resulted in rapid progression of acute lung injury with fatal termination $[47,48]$. The development of acute respiratory distress syndrome in mice challenged by H9N2 viruses was related to local and systemic hyperactive inflammation [49]. Moreover, reduction of inflammation effectively ameliorated H9N2 virus-mediated lung pathology and lung injury [33].

Initiated the expression of cytokines is firstly dependent on virus recognition by cellular PRRs, which results in the activation of multiple signaling pathways [7]. In response to viral infection, the cytosolic sensor RIG-I has been reported to be responsible for JNK activation [50]. JNK signaling cascade transduction mediates phosphorylation of its downstream transcription factor c-jun, which is involved in numerous biological processes, such as proliferation, survival, and inflammation [51, 52]. IVinduced inflammation has been linked to the activity of the JNK/c-jun pathway [53]. IV-mediated upregulation of proinflammatory cytokines (IL-6, TNF- $\alpha$, and CCL5) is JNK-dependent [53]. Moreover, JNK signaling also participates in IV-triggered production of lipid mediators (COX-2 and $\mathrm{PGE}_{2}$ ) [54]. Blockade of JNK signaling significantly ameliorated influenza-associated pneumonia and thus improved high mortality elicited by lethal influenza infections [51]. Pharmacological inhibition of c-jun has been shown to effectively reduce $\mathrm{H} 5 \mathrm{~N} 1$ virusinduced pneumonia [51]. Our results showed that arctiin treatment decreased the IV-mediated activation of JNK signaling. Based on the evidence shown above, we suppose that the inhibitory effects of arctiin on IV-induced inflammation are based on the suppression of JNK activation. Interestingly, we found that the inhibitory effect of arctiin on H9N2 virus-induced activation of JNK was reversed by an HO-1 inhibitor, indicating that the antiinflammatory properties of arctiin depend on the activation of Nrf2/HO-1 signaling. Indeed, previous reports have suggested that the activation of $\mathrm{Nrf} 2 / \mathrm{HO}-1$ signaling has capacity to inhibit NF-kB, P38, and JNK signaling pathways and thus prevent IV-mediated uncontrolled proinflammatory reaction [55-57]. Nrf2 or HO-1 inhibition abrogated the anti-inflammatory effects exerted by various bioactive agents $[58,59]$. A recent study has revealed that arctiin prevented triptolide-induced acute live damage through activation of Nrf2 signaling [60]. Likewise, our findings showed that the blockade of HO-1 reversed the suppression effect of arctiin on H9N2 viruselevated proinflammatory mediators (IL-6, TNF- $\alpha$, COX2 , and $\mathrm{PGE}_{2}$ ). Therefore, we concluded that the activated $\mathrm{Nrf2/HO}-1$ pathway is likely to contribute to the antiinflammatory properties of arctiin in response to H9N2 virus infection.

\section{Conclusions}

In conclusion, we showed that the lignan glycoside arctiin from Arctium lappa L. activated Nrf2/HO-1 signaling, leading to inhibitory effects on RIG-I/JNK signaling. It showed potential inhibitory effects on replication of $\mathrm{H} 9 \mathrm{~N} 2$ virus and $\mathrm{H} 9 \mathrm{~N} 2$ virus-mediated inflammation, so it may be a novel candidate for the development of antiinfluenza agents.

\section{Abbreviations}

AIV: Avian influenza virus; ATCC: American Type Culture Collection; HO-1: Heme oxygenase-1; IFN- $\beta$ : Interferon beta; IL-6: Interleukin 6; IL-8: Interleukin 8; IP-10: Interferon-gamma induced protein 10; IV: Influenza virus; MOI: Multiplicities of infection; Nrf2: NF-E2-related factor 2; PRA: Plaque reduction assay; PRR: Pattern recognition receptor; SD: Standard deviation; SOD2: Superoxide dismutase 2; TNF-a: Tumor necrosis factor alpha.

\section{Supplementary Information}

The online version contains supplementary material available at https://doi. org/10.1186/s12906-021-03462-4.

Additional file 1.

Acknowledgements

Not applicable.

\section{Authors' contributions}

Conceived and designed the experiments: Jing Li and Xiping Pan. Performed the experiments: Beixian Zhou, Linxin Wang, and Yueyun Liang. Analyzed the data: Jing Li, Xiping Pan, and Beixian Zhou. Wrote and revised the paper: Beixian Zhou, Jing Li, and Xiping Pan. The authors read and approved the final manuscript.

Authors' information

Not applicable.

\section{Funding}

This work was supported by Natural Science Foundation of Guangdong Province (Grant no. 2018A030310172), National Natural Science Foundation of China (Grant nos. 82004155 and 82004034), and Guangzhou Science and Technology Plan Project (Grant no. 202102010215).

Availability of data and materials

The datasets used and analyzed during the current study are available from the corresponding author on reasonable request.

\section{Declarations}

Ethics approval and consent to participate Not applicable. 


\section{Consent for publication \\ Not applicable.}

\section{Competing interests}

The authors declare that there are no conflicts of interests.

\begin{abstract}
Author details
${ }^{1}$ Center of stem cell and Regenerative Medicine, The People's Hospital of Gaozhou, Gaozhou, China. ${ }^{2}$ Guangzhou Laboratory, No. 9, XingDaoHuanBei Road, Guangzhou International Bio Island, Guangzhou 510005, China. ${ }^{3}$ Department of Anesthesiology, The People's Hospital of Gaozhou, Gaozhou, China. ${ }^{4}$ State Key Laboratory of Respiratory Disease, National Clinical Research Center of Respiratory Disease, Guangzhou Institute of Respiratory Health, the First Affiliated Hospital of Guangzhou Medical University, Guangzhou Medical University, NO. 195, Dongfengxi Road, Guangzhou 510120, China. ${ }^{5}$ Institute of Chinese Integrative Medicine, Guangzhou Medical University, Guangzhou, Guangdong, China.
\end{abstract}

Received: 19 July 2021 Accepted: 10 November 2021

Published online: 26 November 2021

\section{References}

1. Homme PJ, Easterday BC. Avian influenza virus infections. I. Characteristics of influenza A-turkey-Wisconsin-1966 virus. Avian Dis. 1970;14(1):66-74.

2. Bergervoet SA, Pritz-Verschuren SBE, Gonzales JL, Bossers A, Poen MJ, Dutta J, et al. Circulation of low pathogenic avian influenza (LPAI) viruses in wild birds and poultry in the Netherlands, 2006-2016. Sci Rep. 2019;9(1):13681.

3. Wang S, Jiang N, Shi W, Yin H, Chi X, Xie Y, et al. Co-infection of H9N2 Influenza A Virus and Escherichia coli in a BALB/C Mouse Model Aggravates Lung Injury by Synergistic Effects. Front Microbiol. 2021;12:670688.

4. Li S, Zhou Y, Song W, Pang Q, Miao Z. Avian influenza virus H9N2 seroprevalence and risk factors for infection in occupational poultry-exposed workers in Tai'an of China. J Med Virol. 2016;88(8):1453-6.

5. Bi Y, Xie Q, Zhang S, Li Y, Xiao H, Jin T, et al. Assessment of the internal genes of influenza $A$ (H7N9) virus contributing to high pathogenicity in mice. J Virol. 2015;89(1):2-13.

6. Arai Y, Ibrahim MS, Elgendy EM, Daidoji T, Ono T, Suzuki Y, et al. Genetic Compatibility of Reassortants between Avian H5N1 and H9N2 Influenza Viruses with Higher Pathogenicity in Mammals. J Virol. 2019;93(4):e01969-18.

7. Carty M, Guy C, Bowie AG. Detection of Viral Infections by Innate Immunity. Biochem Pharmacol. 2021;183:114316.

8. Yoneyama M, Onomoto K, Jogi M, Akaboshi T, Fujita T. Viral RNA detection by RIG-I-like receptors. Curr Opin Immunol. 2015;32:48-53.

9. Ehrhardt C, Seyer R, Hrincius ER, Eierhoff T, WolffT, Ludwig S. Interplay between influenza $A$ virus and the innate immune signaling. Microbes Infect. 2010;12(1):81-7.

10. Betakova T, Kostrabova A, Lachova V, Turianova L. Cytokines Induced During Influenza Virus Infection. Curr Pharm Des. 2017;23(18):2616-22.

11. Pinto R, Herold S, Cakarova L, Hoegner K, Lohmeyer J, Planz O, et al. Inhibition of influenza virus-induced NF-kappaB and Raf/MEK/ERK activation can reduce both virus titers and cytokine expression simultaneously in vitro and in vivo. Antivir Res. 2011;92(1):45-56.

12. Marjuki H, Alam Ml, Ehrhardt C, Wagner R, Planz O, Klenk HD, et al. Membrane accumulation of influenza A virus hemagglutinin triggers nuclear export of the viral genome via protein kinase Calpha-mediated activation of ERK signaling. J Biol Chem. 2006;281(24):16707-15.

13. König R, Stertz S, Zhou Y, Inoue A, Hoffmann HH, Bhattacharyya S, et al. Human host factors required for influenza virus replication. Nature. 2010;463(7282):813-7.

14. Niture SK, Khatri R, Jaiswal AK. Regulation of Nrf2-an update. Free Radic Biol Med. 2014;66:36-44.

15. Guo Y, Tu YH, Wu X, Ji S, Shen JL, Wu HM, et al. ResolvinD1 Protects the Airway Barrier Against Injury Induced by Influenza A Virus Through the Nrf2 Pathway. Front Cell Infect Microbiol. 2020;10:616475.

16. Velagapudi R, El-Bakoush A, Olajide OA. Activation of Nrf2 Pathway Contributes to Neuroprotection by the Dietary Flavonoid Tiliroside. Mol Neurobiol. 2018;55(10):8103-23.
17. Ren J, Su D, Li L, Cai H, Zhang M, Zhai J, et al. Anti-inflammatory effects of Aureusidin in LPS-stimulated RAW264.7 macrophages via suppressing NF-KB and activating ROS- and MAPKs-dependent Nrf2/HO-1 signaling pathways. Toxicol Appl Pharmacol. 2020;387:114846.

18. Kosmider B, Messier EM, Janssen WJ, Nahreini P, Wang J, Hartshorn KL, et al. Nrf2 protects human alveolar epithelial cells against injury induced by influenza A virus. Respir Res. 2012;13(1):43.

19. Ma Z, Lu Y, Yang F, Li S, He X, Gao Y, et al. Rosmarinic acid exerts a neuroprotective effect on spinal cord injury by suppressing oxidative stress and inflammation via modulating the Nrf2/HO-1 and TLR4/NF-KB pathways. Toxicol Appl Pharmacol. 2020;397:115014.

20. Ma LL, Wang HQ, Wu P, Hu J, Yin JQ, Wu S, et al. Rupestonic acid derivative $\mathrm{YZH}-106$ suppresses influenza virus replication by activation of heme oxygenase-1-mediated interferon response. Free Radic Biol Med. 2016;96:347-61.

21. Lee YJ, Choi DH, Cho GH, Kim JS, Kang DG, Lee HS. Arctium lappa ameliorates endothelial dysfunction in rats fed with high fat/cholesterol diets. BMC Complement Altern Med. 2012;12:116.

22. Lou Z, Li C, Kou X, Yu F, Wang H, Smith GM, et al. Antibacterial, Antibiofilm Effect of Burdock (Arctium lappa L.) Leaf Fraction and Its Efficiency in Meat Preservation. J Food Prot. 2016;79(8):1404-9.

23. Chen J, Li W, Jin E, He Q, Yan W, Yang H, et al. The antiviral activity of arctigenin in traditional Chinese medicine on porcine circovirus type 2. Res Vet Sci. 2016;106:159-64.

24. Sohn EH, Jang SA, Joo H, Park S, Kang SC, Lee CH, et al. Anti-allergic and anti-inflammatory effects of butanol extract from Arctium Lappa L. Clin Mol Allergy. 2011;9(1):4

25. Liu J, Cai YZ, Wong RN, Lee CK, Tang SC, Sze SC, et al. Comparative analysis of caffeoylquinic acids and lignans in roots and seeds among various burdock (Arctium lappa) genotypes with high antioxidant activity. J Agric Food Chem. 2012;60(16):4067-75.

26. Wu X, Zhang N, Kan J, Tang S, Sun R, Wang Z, et al. Polyphenols from Arctium lappa $L$ ameliorate doxorubicin-induced heart failure and improve gut microbiota composition in mice. J Food Biochem. 2021;00:e13731.

27. Gao Q, Yang M, Zuo Z. Overview of the anti-inflammatory effects, pharmacokinetic properties and clinical efficacies of arctigenin and arctiin from Arctium lappa L. Acta Pharmacol Sin. 2018;39(5):787-801.

28. Zhou B, Weng G, Huang Z, Liu T, Dai F. Arctiin Prevents LPS-Induced Acute Lung Injury via Inhibition of PI3K/AKT Signaling Pathway in Mice. Inflammation. 2018:41(6):2129-35.

29. Hayashi K, Narutaki K, Nagaoka Y, Hayashi T, Uesato S. Therapeutic effect of arctiin and arctigenin in immunocompetent and immunocompromised mice infected with influenza A virus. Biol Pharm Bull. 2010;33(7):1199-205.

30. Matrosovich M, Matrosovich T, Garten W, Klenk HD. New low-viscosity overlay medium for viral plaque assays. Virol J. 2006;3:63.

31. Livak KJ, Schmittgen TD. Analysis of relative gene expression data using real-time quantitative PCR and the 2(-Delta Delta C(T)) Method. Methods (San Diego, Calif). 2001;25(4):402-8.

32. Jing L, Yu N, Zhao Y, Li Y. Trace chemical constituents contained in Trachelospermum jasminoides and structure identification. Zhongguo Zhong Yao Za Zhi. 2012;37(11):1581-5.

33. Zhang RH, Zhang HL, Li PY, Gao JP, Luo Q, Liang T, et al. Autophagy is involved in the acute lung injury induced by H9N2 influenza virus. Int Immunopharmacol. 2019;74:105737.

34. Xu X, Zeng XY, Cui YX, Li YB, Cheng JH, Zhao XD, et al. Antidepressive Effect of Arctiin by Attenuating Neuroinflammation via HMGB1/TLR4and TNF-a/TNFR1-Mediated NF-KB Activation. ACS Chem Neurosci. 2020;11(15):2214-30.

35. Coulombe F, Jaworska J, Verway M, Tzelepis F, Massoud A, Gillard J, et al. Targeted prostaglandin E2 inhibition enhances antiviral immunity through induction of type I interferon and apoptosis in macrophages. Immunity. 2014;40(4):554-68.

36. Lampejo T. Influenza and antiviral resistance: an overview. Eur J Clin Microbiol Infect Dis. 2020;39(7):1201-8.

37. Bae S, Lim KM, Cha HJ, An IS, Lee JP, Lee KS, et al. Arctiin blocks hydrogen peroxide-induced senescence and cell death though microRNA expression changes in human dermal papilla cells. Biol Res. 2014;47(1):50.

38. Lee JH, Kim C, Lee J, Um JY, Sethi G, Ahn KS. Arctiin is a pharmacological inhibitor of STAT3 phosphorylation at tyrosine 705 residue and 
potentiates bortezomib-induced apoptotic and anti-angiogenic effects in human multiple myeloma cells. Phytomedicine. 2019;55:282-92.

39. Dias MM, Zuza O, Riani LR, de Faria PP, Pinto PLS, Silva MP, et al. In vitro schistosomicidal and antiviral activities of Arctium lappa L. (Asteraceae) against Schistosoma mansoni and Herpes simplex virus-1. Biomed Pharmacother. 2017;94:489-98.

40. Ludwig S, Planz O, Pleschka S, WolffT. Influenza-virus-induced signaling cascades: targets for antiviral therapy? Trends Mol Med. 2003;9(2):46-52.

41. Zhang S, Tian H, Cui J, Xiao J, Wang M, Hu Y. The c-Jun N-terminal kinase (JNK) is involved in H5N1 influenza A virus RNA and protein synthesis. Arch Virol. 2016;161(2):345-51.

42. Sharma A, Batra J, Stuchlik O, Reed MS, Pohl J, Chow VTK, et al. Influenza A Virus Nucleoprotein Activates the JNK Stress-Signaling Pathway for Viral Replication by Sequestering Host Filamin A Protein. Front Microbiol. 2020;11:581867.

43. Kesic MJ, Simmons SO, Bauer R, Jaspers I. Nrf2 expression modifies influenza A entry and replication in nasal epithelial cells. Free Radic Biol Med. 2011;51(2):444-53.

44. Zhong M, Wang H, Ma L, Yan H, Wu S, Gu Z, et al. DMO-CAP inhibits influenza virus replication by activating heme oxygenase-1-mediated IFN response. Virol J. 2019;16(1):21.

45. Lee S, Shin S, Kim H, Han S, Kim K, Kwon J, et al. Anti-inflammatory function of arctiin by inhibiting COX-2 expression via NF-KB pathways. J Inflamm (London, England). 2011;8(1):16.

46. Vareille M, Kieninger E, Edwards MR, Regamey N. The airway epithelium: soldier in the fight against respiratory viruses. Clin Microbiol Rev. 2011;24(1):210-29.

47. Zhou J, Guo X, Fang D, Yu Y, Si L, Wang Y, et al. Avian Influenza A (H7N9) viruses isolated from patients with mild and fatal infection differ in pathogenicity and induction of cytokines. Microb Pathog. 2017;111:402-9.

48. Ramos I, Fernandez-Sesma A. Innate immunity to $\mathrm{H} 5 \mathrm{~N} 1$ influenza viruses in humans. Viruses. 2012;4(12):3363-88.

49. Deng G, Bi J, Kong F, Li X, Xu Q, Dong J, et al. Acute respiratory distress syndrome induced by H9N2 virus in mice. Arch Virol. 2010;155(2):187-95.

50. Mosallanejad K, Sekine Y, Ishikura-Kinoshita S, Kumagai K, Nagano T, Matsuzawa A, et al. The DEAH-box RNA helicase DHX15 activates NF-KB and MAPK signaling downstream of MAVS during antiviral responses. Sci Signal. 2014;7(323):ra40.

51. Xie J, Zhang S, Hu Y, Li D, Cui J, Xue J, et al. Regulatory roles of C-jun in H5N1 influenza virus replication and host inflammation. Biochim Biophys Acta. 2014;1842(12 Pt A):2479-88.

52. Ma J, Zhang L, Han W, Shen T, Ma C, Liu Y, et al. Activation of JNK/c-Jun is required for the proliferation, survival, and angiogenesis induced by EET in pulmonary artery endothelial cells. J Lipid Res. 2012;53(6):1093-105.

53. Gao W, Sun W, Qu B, Cardona CJ, Powell K, Wegner M, et al. Distinct regulation of host responses by ERK and JNK MAP kinases in swine macrophages infected with pandemic (H1N1) 2009 influenza virus. PLoS One. 2012;7(1):e30328.

54. Mizumura K, Hashimoto S, Maruoka S, Gon Y, Kitamura N, Matsumoto K, et al. Role of mitogen-activated protein kinases in influenza virus induction of prostaglandin E2 from arachidonic acid in bronchial epithelial cells. Clin Exp Allergy. 2003;33(9):1244-51.

55. Du Y, Wang Q, Tian N, Lu M, Zhang XL, Dai SM. Knockdown of nrf2 Exacerbates TNF-a-Induced Proliferation and Invasion of Rheumatoid Arthritis Fibroblast-Like Synoviocytes through Activating JNK Pathway. J Immunol Res. 2020;2020:6670464.

56. Lu C, Fan G, Wang D. Akebia Saponin D ameliorated kidney injury and exerted anti-inflammatory and anti-apoptotic effects in diabetic nephropathy by activation of NRF2/HO-1 and inhibition of NF-KB pathway. Int Immunopharmacol. 2020;84:106467.

57. Wang D, Chen T, Liu F. Betulinic acid alleviates myocardial hypoxia/ reoxygenation injury via inducing $\mathrm{Nrf2/HO}-1$ and inhibiting p38 and JNK pathways. Eur J Pharmacol. 2018;838:53-9.

58. Chen $\mathrm{HG}$, Xie KL, Han HZ, Wang WN, Liu DQ, Wang GL, et al. Heme oxygenase-1 mediates the anti-inflammatory effect of molecular hydrogen in LPS-stimulated RAW 264.7 macrophages. Int J Surg. 2013;1 1(10):1060-6.

59. Dai JP, Wang QW, Su Y, Gu LM, Zhao Y, Chen XX, et al. Emodin Inhibition of Influenza A Virus Replication and Influenza Viral Pneumonia via the Nrf2, TLR4, p38/JNK and NF-kappaB Pathways. Molecules. 2017;22(10):1754.
60. Zhou Y, Xia L, Yao W, Han J, Wang G. Arctiin Antagonizes TriptolideInduced Hepatotoxicity via Activation of Nrf2 Pathway. Biomed Res Int. 2020;2020:2508952.

\section{Publisher's Note}

Springer Nature remains neutral with regard to jurisdictional claims in published maps and institutional affiliations.
Ready to submit your research? Choose BMC and benefit from:

- fast, convenient online submission

- thorough peer review by experienced researchers in your field

- rapid publication on acceptance

- support for research data, including large and complex data types

- gold Open Access which fosters wider collaboration and increased citations

- maximum visibility for your research: over $100 \mathrm{M}$ website views per year

At BMC, research is always in progress.

Learn more biomedcentral.com/submissions 